\title{
Serum Cortisol Levels in Maternal \\ Venous, Umbilical Arterial and \\ Umbilical Venous Blood at Delivery in the Cases of Fetal Distress
}

\author{
Hideaki Kohno, Nobuaki Furuhashi, Takao Fukaya, \\ Osamu Shinkawa, Yoshinobu Tachibana and Masakuni \\ SUZUKI \\ Department of Obstetrics and Gynecology, Tohoku \\ University School of Medicine, Sendai 980
}

\begin{abstract}
Kohno, H., Furuhashi, N., Fukaya, T., Shinkawa, O., Tachibana, Y. and Suzuki, M. Serum Cortisol Levels in Maternal Venous, Umbilical Arterial and Umbilical Venous Blood at Delivery in the Cases of Fetal Distress. Tohoku J. exp. Med., 1984, 144 (3), 299-304 — We measured maternal venous (MV), umbilical arterial (UA) and umbilical venous (UV) cortisol levels in 180 term pregnancies to investigate the changes of these hormone levels in the cases of fetal distress and neonatal asphyxia. The cortisol levels in UA and UV blood in the fetal distress group were significantly higher than those in the non-fetal distress group among spontaneous vaginal delivery cases. There were significant positive correlations among the cortisol levels in MV and UA, MV and UV, and UA and UV blood, respectively. These data suggest that in the case of fetal distress or neonatal asphyxia, mother and fetus have responded independently to the stress of delivery, and that maternal cortisol might not strongly affect the fetal cortisol secretion.— cortisol ; maternal serum; fetal serum; fetal distress; neonatal asphyxia
\end{abstract}

It has been suggested that the cortisol secretion of mother and fetus increases in response to the stress of delivery (Ohlander et al. 1976). However, there were only a few reports about the reaction of the adrenocortical glands of the mother and fetus in the cases of fetal distress and neonatal asphyxia. In this study, we measured serum cortisol levels in maternal venous (MV), umbilical arterial (UA) and umbilical venous (UV) blood after delivery, and investigated the maternal and fetal cortisol levels, especially in relation to the fetal distress and neonatal asphyxia.

\section{Materials and Methods}

Subjects. We analyzed 180 term deliveries (105 spontaneous vaginal deliveries, 41 vacuum extractions, 26 cesarean sections and 8 breech extractions). Maternal blood was

Received for publication, March 15, 1984. 
drawn from the antecubital vein immediately after delivery. UA and UV blood was collected after birth clamping the cord at two points. The samples were centrifuged and the serum was kept at $-20^{\circ} \mathrm{C}$ until assay. All deliveries had been monitored by the electric fetal heart rate monitoring system model FMS-112 (Colometrics Co., California, USA). The criteria for fetal distress were persistent bradycardia, severe late deceleration and severe variable deceleration of heart rate. The diagnosis of neonatal asphyxia was made in cases with Apgar score of less than 6 at one minute. All delivery cases had shown good Apgar score (more than 7) in 5 min Apgar score. All infants were healthy at the physial examination 1 month later. The anesthesia was not applied for deliveries except for cesarean section. In the cesarean section cases, 18 cases had no labor, but 8 had it.

Radioimmunoassay. Serum cortisol was measured as previously reported (Furuhashi et al. 1982) using cortisol radioimmunoassay kit (Daiichi Radioisotope Laboratory, Tokyo). The coefficients of variation of this method was less than $10 \%$.

Statistical analysis. Statistical analysis was performed with Student's $t$-test. Correlation coefficients, analysis of variance and covariance were calculated by a microcomputer TRS-80 (Radio Shack, Fortworth, Texas, USA).

\section{Results}

The cortisol levels in MV, UA and UV blood were lowest in the cesarean section group in the cases of normal fetus and neonate. In spontaneous vaginal delivery, the cortisol levels in MV and UA blood were not significantly different from those in breech extraction. On the other hand, the cortisol levels in UV blood were significantly $(p<0.02)$ higher in breech extraction than in spontaneous

TABLE 1. Serum cortisol levels classified by the mode of delivery in the cases without fetal distress or neonatal asphyxia

\begin{tabular}{lccc}
\hline \multirow{3}{*}{ Blood } & \multicolumn{3}{c}{ Mode of delivery } \\
\cline { 2 - 4 } & $\begin{array}{c}\text { Spontaneous vaginal } \\
(n=94)\end{array}$ & $\begin{array}{c}\text { Breech extraction } \\
(n=6)\end{array}$ & $\begin{array}{c}\text { Cesarean section } \\
(n=18)\end{array}$ \\
\hline Maternal vein & $75.0 \pm 22.2^{a}$ & $82.5 \pm 16.3^{a, b}$ & $55.8 \pm 14.4^{a, b}$ \\
Umbilical artery & $13.6 \pm 5.2^{c}$ & $15.0 \pm 4.3^{d}$ & $8.5 \pm 3.2^{c, d}$ \\
Umbilical vein & $10.6 \pm 5.1^{e, f}$ & $15.7 \pm 5.9^{e, g}$ & $7.0 \pm 2.4^{f, g}$ \\
\hline
\end{tabular}

Values are expressed as $\mu \mathrm{g} / 100 \mathrm{ml}$ (mean \pm S.D.).

e $p<0.02,{ }^{f} p<0.01,{ }_{a, b, c, d, g} p<0.001$.

TABLE 2. Serum cortisol levels classified by the mode of delivery in the cases without fetal distress or neonatal asphyxia

\begin{tabular}{lccc}
\hline & \multicolumn{3}{c}{ Mode of delivery } \\
\cline { 2 - 4 } Blood & $\begin{array}{c}\text { Spontaneous vaginal } \\
(n=94)\end{array}$ & $\begin{array}{c}\text { Breech extraction } \\
(n=6)\end{array}$ & $\begin{array}{c}\text { Cesarean section } \\
(n=18)\end{array}$ \\
\hline Maternal vein & $75.0 \pm 22.2^{a, b}$ & $82.5 \pm 16.3^{d, e}$ & $55.8 \pm 14.4^{f, g}$ \\
Umbilical artery & $13.6 \pm 5.2^{a, c}$ & $15.0 \pm 4.3^{d}$ & $8.5 \pm 3.2^{f, h}$ \\
Umbilical vein & $10.6 \pm 5.1^{b, c}$ & $15.7 \pm 5.9^{e}$ & $7.0 \pm 2.4^{g, b}$ \\
\hline
\end{tabular}

Values are expressed as $\mu \mathrm{g} / 100 \mathrm{ml}$ (mean \pm S.D.).

${ }^{b} p<0.002$, a,b,c,d,e,f,g$p<0.0001$. 


\begin{tabular}{ccc}
$\begin{array}{c}\text { TABLE 3. Serum cortisol levels at spontaneous vaginal } \\
\text { deliveries }\end{array}$ & \multicolumn{2}{c}{ Fetal distress } \\
\hline Blood & $(+)(n=8)$ & $(-)(n=97)$ \\
\hline Maternal vein & $68.5 \pm 21.2$ & $74.6 \pm 22.1$ \\
Umbilical artery & $21.4 \pm 14.5^{a}$ & $13.6 \pm 5.2^{a}$ \\
Umbilical vein & $18.2 \pm 16.8^{b}$ & $10.6 \pm 5.1^{b}$ \\
\hline Values are expressed as & $\mu \mathrm{g} / 100 \mathrm{ml}$ (mean \pm s.D. $).$ \\
a,b $p<0.01$. & \multicolumn{2}{c}{ Fetal distress } \\
TABLE 4. & Cortisol levels at cesarean section \\
\hline Blood & $(+)(n=6)$ & $(-)(n=20)$ \\
\hline Maternal vein & $48.8 \pm 20.3$ & $54.4 \pm 14.4$ \\
Umbilical artery & $15.0 \pm 10.1^{a}$ & $8.8 \pm 3.7^{a}$ \\
Umbilical vein & $11.5 \pm 6.4^{b}$ & $7.4 \pm 3.1^{b}$ \\
\hline
\end{tabular}

Values are expressed as $\mu \mathrm{g} / 100 \mathrm{ml}$ (mean \pm S.D.).

${ }^{b} p<0.05, \quad$ a $p<0.04$.

TABLE 5. Serum cortisol levels at spontaneous vaginal deliveries

\begin{tabular}{lcc}
\hline \multicolumn{1}{c}{ Blood } & \multicolumn{2}{c}{ Neonatal asphyxia } \\
& $(+)(n=6)$ & $(-)(n=99)$ \\
\hline Maternal vein & $76.7 \pm 18.4$ & $74.0 \pm 22.3$ \\
Umbilical artery & $21.6 \pm 12.7^{a}$ & $13.7 \pm 5.9^{a}$ \\
Umbilical vein & $17.8 \pm 15.4^{b}$ & $10.8 \pm 5.9^{b}$ \\
\hline
\end{tabular}

Values are expressed as $\mu \mathrm{g} / 100 \mathrm{ml}$ (mean \pm S.D.).

${ }^{b} p<0.02,{ }^{a} p<0.01$.

vaginal delivery (Table 1 ).

As shown in Table 2, cortisol levels were significantly $(p<0.002 \sim 0.0001)$ higher in MA than in UA or UV blood. In cases of spontaneous vaginal delivery and cesarean section, cortisol levels in UA blood were significantly $(p<0.0001)$ higher than those in UV blood.

There were 8 fetal distress cases in spontaneous vaginal deliveries as shown in Table 3. The cortisol level in MV blood was not affected by fetal distress. Cortisol levels in UA and UV blood were significantly $(p<0.01)$ higher in the fetal distress group than in the non-fetal distress group.

In the cesarean section group, there were 6 fetal distress cases, of which 3 cases were accompanied by neonatal asphyxia (Table 4). The cortisol levels in UA and UV blood were significantly $(p<0.05)$ higher in the fetal distress cases than in the non-fetal distress cases.

The maternal cortisol levels in the cases of spontaneous vaginal delivery with 
TABLE 6. Correlations among the cortisol levels in maternal venous (MV), umbilical arterial (UA) and umbilical venous (UV) blood

\begin{tabular}{lclll}
\hline \multicolumn{1}{c}{ Clinical status } & $\begin{array}{c}\text { Numbers of } \\
\text { cases }\end{array}$ & Sample & $r$ & $p$ \\
\hline $\begin{array}{l}\text { Fetal distress } \\
\text { group }\end{array}$ & 55 & MV vs. UA & 0.414 & $<0.001$ \\
$\begin{array}{l}\text { Non-fetal distress } \\
\text { group }\end{array}$ & 125 & MV vs. UV & 0.459 & $<0.001$ \\
\hline $\begin{array}{l}\text { Neonatal asphyxia } \\
\text { group }\end{array}$ & 15 & MV vs. UA & 0.5 & $<0.001$ \\
$\begin{array}{l}\text { Non-neonatal asphyxia } \\
\text { group }\end{array}$ & \multirow{2}{*}{ MV vs. UA } & 0.687 & $<0.001$ \\
\hline $\begin{array}{l}\text { All cases } \\
\text { MV vs. UV }\end{array}$ & MV vs. UA & 0.582 & $<0.491$ & $<0.01$ \\
& \multirow{2}{*}{180} & MV vs. UV & 0.644 & $<0.001$ \\
\hline
\end{tabular}

TABLE 7. Correlation between the cortisol levels for umbilical artery and umbilical vein

\begin{tabular}{lccc}
\hline \multicolumn{1}{c}{ Clinical status } & Number of cases & $r$ & $p$ \\
\hline $\begin{array}{l}\text { Fetal disterss } \\
\text { group }\end{array}$ & 55 & 0.913 & $<0.001$ \\
$\begin{array}{l}\text { Non-fetal distress } \\
\text { group }\end{array}$ & 125 & 0.746 & $<0.001$ \\
\hline $\begin{array}{l}\text { Neonatal asphyxia } \\
\text { group }\end{array}$ & 15 & 0.975 & $<0.001$ \\
$\begin{array}{l}\text { Non-neonatal asphyxia } \\
\text { group }\end{array}$ & 165 & 0.816 & $<0.001$ \\
\hline All cases & 180 & 0.845 & $<0.001$ \\
\hline
\end{tabular}

neonatal asphyxia were not different from the corresponding values in the cases without neonatal asphyxia. The neonatal asphyxia cases had significantly $(p<$ 0.02) higher cortisol levels in the UA and UV blood than the non-neonatal asphyxia cases (Table 5).

There were positive correlations among cortisol levels in MV, UA and UV blood (Table 6). The cortisol levels in UA blood had significantly $(p<0.001)$ positive correlations with those in UV blood in all cases (Table 7).

\section{Discussion}

It has been reported that maternal cortisol levels increased until term, and that the near term levels were 3 times higher than the 1st trimester levels (Gibson and Tulchinsky 1980). The details of the alteration of cortisol secretion when the fetus is severely stressed at delivery are still unclear. It was speculated that the level of maternal and fetal cortisol secretion changes in response to stress, such as 
strength of labor (Burns 1976), duration of labor (Maltau et al. 1979), and maternal anxiety (Lederman et al. 1978). Cawson et al. (1974) reported that the cortisol level in MV blood was higher in vacuum extraction than in spontaneous vaginal delivery or cesarean section, and that maternal cortisol levels in spontaneous vaginal delivery were higher than those in cesarean section. In our cases, maternal cortisol levels in spontaneous vaginal delivery and breech extraction were higher than those in cesarean section. There were a few reports about the maternal cortisol levels in breech extraction. The cortisol levels in UA and UV blood in spontaneous vaginal delivery and breech extraction were higher than those in cesarean section. In breech extraction, cortisol levels in UV blood were higher than those in spontaneous vaginal delivery, and it was suggested that the fetus in breech extraction was more stressed than in spontaneous vaginal delivery.

It was reported that the cortisol levels in UA blood increased 2-3 times in 3035 weeks' gestation, and 4-5 times in 36-38 weeks' compared with the cortisol levels in 20 weeks'. It was speculated that in the 3rd trimester of pregnancy, false pains began as a sign of delivery, fetus became large, intrauterine pressure increased, the placenta matured and fetal cortisol levels increased (Murphy et al. 1980). The maternal cortisol level was higher than those in UA and UV blood. The cortisol level in UA blood was higher than that in UV blood except breech extraction. Cortisol levels in UA blood in spontaneous vaginal delivery and cesarean section were significantly $(p<0.0001)$ higher than those in UV blood (Table 2). These data suggest that fetus might respond to the stress of delivery and increase the secretion of cortisol.

We found that there was no significant difference in maternal cortisol level between the fetal distress group and non-fetal distress group. Also, the cortisol levels in UA and UV blood were significantly $(p<0.05 \sim 0.01)$ higher in the fetal distress group than in the group without fetal distress (Tables 3,4 ). These data suggest that the fetal adrenocortex responds to the stress with out maternal effects. There were many reports about fetal cortisol origin and the endocrinological interrelationship between mother and fetus. The fetus might produce cortisol from cholesterol or progesterone itself (Sippel et al. 1981). Cortisone might be converted to cortisol in fetal peripheral tissue (Fencle et al. 1980). There was a transplacental inflow of cortisol from mother to fetus (Predine et al. 1979). It was indicated that dangerous obstetrical factors for fetuses might result in stimulation of fetal cortisol secretion (Ischerwood et al. 1981; Martinsen et al. 1982). We found positive correlations among the cortisol levels of mother, fetus and neonate (Tables 6, 7). These data suggest that not only in favorable cases of fetus, but in unfavorable cases such as fetal distress and neonatal asphyxia, maternal cortisol secretion is not affected by the fetus.

\section{References}

1) Burns, J.K. (1976) Relation between blood levels of cortisol and during of human 
labor. J. Physiol., 254, 12-18.

2) Cawson, M.J., Anderson, A.B.M., Turnbull, A.C. \& Lampe, L. (1974) Cortisol, cortisone and 11-deoxycortisol levels in human umbilical and maternal plasma in relation to the onset of labor. J. Obstet. Gynecol. Brit. Cwlth, 81, 737-745.

3) Davies, I.J. (1980) The fetal adrenal. In: Maternal-Fetal Endocrinology, edited by D. Tulchinsky \& K.J. Ryan, Saunders, Philadelphia, pp. 241-251.

4) Fencle, M.D., Koos, B. \& Tulchinsky, D. (1980) Origin of corticosteroids in amniotic fluid. J. clin. Endocr. Metab., 50, 431-436.

5) Furuhashi, N., Suzuki, M., Fukaya, T., Kono, H., Shinkawa, O., Tachibana, Y. \& Takahashi, T. (1982) Concentrations of LH-hCG, $\beta$-hCG, FSH, estradiol, cortisol and testosterone in cord sera and their correlations. Amer. J. Obstet. Gynecol., 143, 918-921.

6) Gibson, M. \& Tulchinsky, D. (1980) The maternal adrenal. In: Maternal-Fetal Endocrinology, edited by D. Tulchinsky \& K.J. Ryan, Saunders, Philadelphia, pp. 129143.

7) Ischerwood, D.M., Jenkins, D.M. \& Perry, L.A. (1981) Effects of delivery on fetal unbound cortisol concentration. Obstet. Gynecol., 57, 215-219.

8) Lederman, R.P., Lederman, E., Work, B.A. \& Mccann, D.C. (1978) The relationship of maternal anxiety, plasma catecholamines, and plasma cortisol to progress in labor. Amer. J. Obstet. Gynecol., 132, 495-500.

9) Maltau, J.M., Eielsen, O.V.\& Stokke, K.T. (1979) Effect of stress during labor on the concentration of cortisol and estriol in maternal plasma. Amer. J. Obstet. Gynecol., 134, 681-684.

10) Martinsen, K., Peltora, J., Tervila, L. \& Virtanen, A. (1982) Umbilical cord cortisol and arterial $\mathrm{pH}$ levels in spontaneous and induced labors. Obstet. Gynecol., 59, 171175.

11) Murphy, B.E.P., Sebennick, M. \& Patchell, M.E. (1980) Cortisol production and metabolism in the human fetus and its reflection in the maternal urine. J. Steroid Biochem., 12, 37-45.

12) Ohlander, S., Gennser, G. \& Eneroth, P. (1976) Plasma cortisol levels in human fetus during parturition. Obstet. Gynecol., 48, 381-387.

13) Predine, J., Mercerone, L., Barrier, G., Sureau, C. \& Milgrom, E. (1979) Unbound cortisol in umbilical cord plasma and maternal plasma. A reinvestigation. Amer. J. Obstet. Gynecol., 135, 530-542.

14) Sippel, W.G., Muller-Holve, W., Dorr, H.G., Bidlingmaier, F. \& Knorr, D. (1981) Concentrations of aldosterone, corticosterone, 11-deoxycorticosterone, progesterone, 17-hydroxyprogesterone, 11-deoxycortisol, cortisol and cortisone determined simultaneously in human amniotic fluid throughout gestation. J. clin. Endocr. Metab., 52, 385-391. 